\title{
INTERSEXUALIDADE E DIREITO À IDENTIDADE: UMA DISCUSSÃO SOBRE O ASSENTAMENTO CIVIL DE CRIANÇAS INTERSEXUADAS
}

\author{
INTERSEX AND THE RIGHT TO IDENTITY: \\ A DISCOURSE ON THE CIVIL RECORD OF INTERSEX CHILDREN
}

\author{
Roberta Tourinho Dantas Fraser ${ }^{1}$, Isabel Maria Sampaio Oliveira Lima²
}

\begin{abstract}
RESUMO:
O Direito articula-se com o tema da intersexualidade humana a partir da identidade sexual como um subaspecto do direito humano à identidade. A intersexualidade constitui uma circunstância que afeta ocrescimento e o desenvolvimento da criança. O diagnóstico, por vezes retardado em face da necessidade de exames específicos, implica diretamente na definição do sexo e do nome, afetando o assentamento civil da criança. Neste sentido, o presente artigo visa analisar a garantia do direito à identidade da criança com intersexo na perspectiva do Registro Civil de Nascimento, enquanto Direito Humano. Para tanto, foram realizadas entrevistas com profissionais do direito que trabalham nas áreas da infância, família ou registro público. A entrevista levantou opiniões sobre a garantia do direito à identidade destas crianças em face da Lei de Registros Públicos vigente no Brasil. Como resultado, os discursos convergiram para o anacronismo da referida norma e para a necessidade de uma modificação legal a fim de resguardar a dignidade das crianças intersexuadas. O direito à identidade do recém-nascido com intersexo constitui um tema que demanda interlocução com várias áreas do saber e da prática para efetiva garantia do melhor interesse da criança.
\end{abstract}

Palavras-chave: intersexo; direito da criança; registro público; direito à identidade.

\begin{abstract}
:
Law interacts with intersex in humans from the perspective of gender identity, as a sub-aspect of the right to identity. Intersex is a condition affecting the growth and development of children. The diagnosis, sometimes delayed because of the need for specific exams, has a direct effect on gender and name definition, as reflected on a child's civil record. In this sense, the purpose of this article is to examine the intersex children's guarantee to the right to identity, from the perspective of the civil birth record as a human right. To this end, interviews were conducted with legal professionals working with childhood, family or public registry issues. The interviews generated opinions on the guarantee to the right to identity for these children, under the present Brazilian Law of Public Records. As a result, speeches converged on the anachronism in this law, as well as the need for legal changes to preserve the children's dignity. The intersex newborn's right to identity is a subject that demands interaction among various areas of knowledge and practice to effectively guarantee the best interests of the child.
\end{abstract}

Key words: intersex; rights of the child; public record; right to identity.

1 Bachelor of Law and Biology.

2 Human Rights, Right to Health and Family' Research Group Coordinator (CNPq/UCSal)Catholic University of Salvador. Corresponding author: isabelmsol@gmail.com

Suggested citation: Fraser RTD, Lima IMSO. Intersex and the right to identity: a discourse on the civil record of intersex children. J. Hum. Growth Dev. 2012; 22(3): 358-366

Manuscript submitted Jun 28 2012, accepted for publication Aug 302012. 


\section{INTRODUÇÃO}

O presente artigo objetiva discutir a garantia do direito à identidade da criança com intersexo, na perspectiva do Registro Civil de Nascimento como um Direito Humano, em face da Lei de Registros Públicos vigente ${ }^{1}$.

A intersexualidade humana constitui um fenômeno orgânico, oriundo de um desequilíbrio entre os fatores e eventos responsáveis pela determinação e diferenciação sexuais, que se configura quando o indivíduo apresenta ambiguidades, anomalias ou incongruências no componente biológico da sua identidade sexual, ou seja, no seu sexo cromossômico, endócrino e/ou morfológico².

Este fenômeno é de alta complexidade, considerado como uma urgência médica e social quando do nascimento de uma criança, devido aos riscos e aos impactos na vida do indivíduo. É imprescindível a atuação de uma equipe multidisciplinar para o diagnóstico, tratamento e o acompanhamento destas pessoas ${ }^{3}$. Diante das implicações do diagnóstico, com repercussões além dos aspectos biomédicos, é necessária a presença de psicólogos, assistentes sociais e profissionais do direito ${ }^{4}$.

Na defesa dos Direitos Humanos da criança com intersexo, destacam-se, sobretudo, dois componentes: o direito à saúde e o direito à identidade. Estes constituem eixos prioritários para o exercício da dignidade da criança, em virtude da sua condição peculiar de pessoa em desenvolvimento ${ }^{5,6,7}$.

A identidade sexual é um dos elementos constitutivos da identidade humana e se representa, na sociedade brasileira, pela designação do indivíduo como pertencente a um dos sexos: feminino ou masculino. O sexo indica o conjunto de características biopsicossociais que distinguem o macho da fêmea. Atualmente, entende-se que a formação da identidade sexual de um indivíduo é determinada por uma série de eventos concatenados, entre os quais estão tanto elementos biológicos quanto psicossociais ${ }^{8,9}$.

Os elementos biológicos envolvem o sexo genético, o sexo endócrino e o sexo morfológico, originando o aspecto físico do indivíduo. O sexo genético se refere à definição cromossômica, sendo $X X$ mulher e $X Y$ homem. O endócrino é composto pelas gônadas, os testículos nos homens e os ovários nas mulheres, assim como por outras glândulas (hipófise e tireoide) responsáveis por traços de masculinidade e feminilidade. O morfológico está relacionado à aparência dos genitais internos e externos, devendo-se analisar a presença dos caracteres sexuais primários e secundários, observando se existe uma correspondência entre eles ${ }^{10,11,12}$.

Já os elementos psicossociais, que envolvem o sexo psicológico e o sexo social, respectivamente, são definidos a partir de alguns fatores tais como a formação educacional, a influência da família e da sociedade, o comportamento do indivíduo e sua afirmação em determinado gênero ${ }^{13,14,15}$. A concordância entre os sexos genético, endócrino e morfológico de um indivíduo pode ser prejudicada se não houver identificação psicológica dos indivíduos com os sexos em que são classificados (sexo psicológico) e, ainda, a aceitação social dessas pessoas em um ou outro sexo (sexo social).

A definição da identidade sexual do ser humano inclui a integração de um terceiro elemento, além do biológico e do psicossocial, que é o de natureza civil ou legal. Este último, designado por ocasião do Assentamento de Nascimento da criança, baseado eminentemente no aspecto morfológico dos seus genitais externos, consiste na determinação do sexo em razão da vida civil de cada pessoa, em suas relações na sociedade, e traz consigo inúmeras implicações jurídicas ${ }^{14}$.

Portanto, compreende-se que a formação da identidade sexual do individuo é o resultado da integração dos elementos biológico, psicossocial e civil. Neste contexto, a criança intersexuada pode ser entendida como aquela que apresenta distúrbios, anomalias ou incongruências em qualquer dos seus sexos cromossômico, endócrino ou morfológico, ocasionando ambiguidades no componente biológico da sua identidade sexual.

O tema da sexualidade integra a discussão da dignidade humana, pois constitui um atributo personalíssimo da pessoa humana, conforme ressalta Torres ${ }^{16}$ :

Desde a promulgação da Constituição de 1988, a dignidade humana já era reconhecida pela sociedade brasileira como um princípio fundamental e norteador de todo o sistema jurídico, político e social do nosso país. E a sexualidade, como atributo da pessoa humana, já deveria ter sido, desde então, submetida à proteção no âmbito da dignidade humana. Além disso, é preciso lembrar, também, que o Brasil, em face de suas normas e princípios constitucionais, submete-se, também, às normas e princípios de Direitos Humanos, ou seja, de um sistema internacional de proteção do ser humano, especialmente dos mais débeis e fragilizados.

A legislação brasileira vigente é omissa acerca da situação específica da intersexualidade. A disciplina do Registro Civil de Pessoas Naturais (Lei $6.015 / 73$ ) determina o assentamento em prazo de 15 dias após o nascimento da criança exigindo, para tanto, a indicação do seu nome e sexo. Nestes termos, a lei especial impõe aos familiares da criança com intersexo uma determinação legal de remoto cumprimento no prazo de duas semanas ${ }^{1}$.

No que se refere aos estudos acadêmicos e científicos sobre a situação das pessoas intersexuadas, ainda é escasso o interesse pelo assunto e concentrado nos aspectos biomédicos do fenômeno ${ }^{4}$. Em sua revisão de literatura sobre a intersexualidade humana, Canguçu-Campinho, Bastos \& Lima apontam que os artigos científicos produzidos sobre o tema são preponderantemente pertencentes ao campo da Medicina, seguido daqueles que abordam aspectos psicológicos e alguns 
que adentram no campo das Ciências Sociais. As autoras também ressaltam a ausência de publicações em periódicos científicos nacionais sobre o tema na perspectiva do Direito ou do Ativismo Político ${ }^{11}$.

A identidade humana, enquanto dimensão intrínseca, é inerente à pessoa e diz respeito à sua dignidade. Considerando-se a lacuna em relação à produção acadêmica e científica sobre os aspectos sócio-jurídicos da intersexualidade, tem-se que o tema ainda não tem sido suficientemente discutido. Considerando-se que a omissão legislativa quanto ao Registro Civil de crianças com intersexo compromete diretamente o princípio fundamental da dignidade da pessoa humana, configura-se oportuno investigar o assunto.

Desta maneira, o objetivo deste artigo é discutir a garantia do direito à identidade da criança com intersexo, na perspectiva do Registro Civil de Nascimento como um Direito Humano e a luz da Lei de Registros Públicos vigente.

\section{MÉTODO}

Adotou-se uma estratégia qualitativa ${ }^{17}$ para a elaboração deste artigo, cuja origem epistemológica e metodológica reside no projeto macro de pesquisa "Direitos Humanos da Criança e do Jovem com intersexo", integrado ao Grupo de Pesquisa "Direitos Humanos, Direito à Saúde e Família" (CNPq/UCSal). Os dados analisados nesse artigo são oriundos desse projeto, que é desenvolvido por pesquisadores do aludido grupo no ambulatório de genética especial de um hospital público em Salvador/BA desde 2004.

A atuação qualitativa visa o aprofundamento de uma determinada temática ou objeto por familiaridade, pela convivência, ou ainda pela comunicação com atores sociais chave ${ }^{18}$. Na presente investigação, foram realizados procedimentos que, além da revisão de literatura e do levantamento legislativo sobre o tema, demandaram 24 meses de inserção no ambulatório para contextualização do fenômeno ora estudado: observação participante mediante o acompanhamento do atendimento sócio-jurídico de pacientes com intersexo.

Ao longo da investigação, percebeu-se que o nascimento da criança com intersexo enseja um desafio relativo ao seu Registro Civil, uma vez que o diagnóstico para efetiva definição do sexo tarda por motivos diversos. Esta circunstância, reconhecida como recorrente quando da identificação do distúrbio de desenvolvimento sexual (DDS) do neonato, resulta em um limite objetivo à concretização do direito à identidade e à dignidade da criança.

Definiu-se como local de levantamento inicial de dados o ambulatório de genética de um hospital público do Nordeste do Brasil, considerado o único ambulatório de referência na região. Neste serviço 430 pessoas estão cadastradas. Durante o período do projeto foram demandadas algumas ações judiciais para retificação do registro civil da criança intersexuada, uma vez constatado que o sexo e o nome registrados logo após o nascimento não condiziam com o sexo posteriormente diagnosticado pela equipe de saúde e acolhido pelas respectivas famílias.

Esses processos evidenciam a complexidade do tema, exigindo, entre outras diligências, um laudo especial da Genética e da Endocrinologia quando a criança é pequena e, quando a criança está além da primeira infância, um laudo de Psicologia.

Além da observação participante, foram realizadas entrevistas semi-estruturadas com informantes-chave, escolhidos entre os profissionais atuantes na área do Direito relacionados ao tema em estudo, mediante prévia elaboração de roteiro e de Termo de Consentimento Informado.

Como informantes-chave, foram entrevistados três Magistrados, atuantes na Vara de Família, na Vara de Registros Públicos e na Corregedoria do Tribunal de Justiça do Estado da Bahia. O roteiro de entrevista aplicado continha três perguntas fundamentais e, a partir das suas respostas, o tema era aprofundado.

Numa primeira etapa, foi questionado como proceder, com base na atual legislação brasileira, em casos de crianças com ambiguidade genital, diante do dever de Assentamento Civil de Nascimento: (a) defender o seu Registro imediato, correndo-se o risco de uma posterior retificação desse Registro, quando diagnosticado o sexo oposto àquele inicialmente designado, ou (b) defender o retardamento do Registro Civil desta criança, entretanto deixando aquela criança sujeita à inexistência jurídica e, consequentemente, sem acesso aos seus direitos durante o período do diagnóstico?

Posteriormente, a partir do desenvolvimento da resposta anterior, foi indagado se a legislação vigente referente ao Assentamento Civil de Nascimento (Lei n. 6.015/73) seria ou não garantidora do direito à identidade e se resguardava suficientemente a dignidade da criança com intersexo.

Por fim, para aqueles que responderam de forma negativa à questão anterior, foi questionado como seria possível interpretar o artigo $54 \mathrm{da}$ Lei de Registros Públicos, o qual determina a imediata identificação do nome e do sexo do registrando no seu Assentamento Civil de Nascimento, em face de uma criança com ambiguidade genital, a fim de ser garantir a efetividade do seu direito à identidade e a dignidade. Foi também suscitado se haveria outros meios ou alternativas mais específicas para satisfazer o direito à identidade e para assegurar a dignidade da criança com intersexo, sob a perspectiva do seu Assentamento Civil.

Para uma melhor individualização das respostas sustentadas pelos entrevistados, e visando manter o anonimato dos informantes-chave, os entrevistados são identificados, na presente investigação, como "juiz A", "juiz B" e "juiz C". 


\section{RESULTADOS}

No que diz respeito a como proceder em casos de crianças com ambiguidade genital, diante do dever de Assentamento Civil de Nascimento, observou-se um ausência de consenso entre os entrevistados, tanto no modus operandi, quando nas justificativas para as suas escolhas. Entre os profissionais do Direito, a defesa do retardamento do registro até que o diagnostico definitivo seja obtido foi a opção escolhida apenas por um dos juízes, enquanto os demais defenderam o registro imediato da criança.

O "juiz $A^{\prime \prime}$ defendeu o retardamento do Assentamento Civil, tendo apontado a necessidade do judiciário levar em consideração as orientações médicas, ou seja, efetuar o registro apenas quando o parecer da equipe de saúde for definitivo; por outro lado, os juízes "B" e "C" defenderam o imediato Registro Civil de nascimento, ratificando o imperativo legal e a importância de tal documento para efetivação dos direitos do ser humano.

A partir do depoimento dos personagens-chave, revela-se o quão polêmico é o tema e o quão relevante se faz a discussão do Assentamento Civil de crianças intersexuadas, a começar pela ausência de consenso entre os profissionais sobre como proceder diante de tal situação: Registrar imediatamente? Adiar o Registro?

\section{DISCUSSÃO}

\section{O nome e as denominações}

Nomear alguém ou algum fenômeno constitui um processo de respeito e envolve uma relação de cuidado. Tem cada nome uma história, um significado, um pertencimento a uma dada contextualidade familiar, cultural, temporal. O nome da criança recém-nascida traduz uma impressão dos seus pais ou das pessoas que o acolhem. Embora a vertente Psicanalista do autor atribua uma letra maiúscula ao substantivo, Douville enfatiza:

Há no Nome Próprio algo insubstituível, posto que há a alteridade indivisível que aparece e recolhe a epopeia de uma memória imemorial. Há um Nome próprio quando alguma coisa de um elo se estabelece entre uma voz e uma letra, quando uma afinidade está em jogo entre um eu, um corpo e o dom de uma letra que não vem de lugar nenhum. Intraduzível, exceto quanto a fazer dele quase um insulto ou uma ridicularia frágil e fragilizante, o nome, em razão de sua amarra literal, é dotado para a viagem, e talvez mesmo seja aplicado exclusivamente à viagem, posto que não são somente os homens que migram, mas também as palavras e as letras se deslocam e se transferem. ${ }^{19}$

A precisão diagnóstica também demanda uma nomeação. Cada pessoa deseja conhecer o nome do que se lhe ocorre, reconhecer-se naquele nome que, embora da área médica, constitui uma definição para o enfrentamento do seu caso clínico. A família da criança com intersexo vivencia esta du- pla expectativa entre nomear o bebê e saber o nome daquilo que a criança tem.

O fenômeno complexo da intersexualidade já foi denominado de Anomalia do Desenvolvimento Sexual (ADS) ou Distúrbio da Diferenciação Sexual (DDS). Terminologicamente ainda não há um consenso na comunidade científica sobre o termo adequado ao fenômeno. A tentativa da adoção de uma nomenclatura definitiva e generalizada ao estado de intersexualidade aconteceu em 2005, no Consenso de Chicago, realizado em Chicago (EUA), entretanto não logrou êxito neste aspecto ${ }^{20}$.

Contudo, percebe-se que no campo das Ciências Sociais a preferência é pela adoção dos termos intersexo e intersexualidade, enquanto que no campo Biomédico utilizam-se preferencialmente as nomenclaturas ADS ou DDS. No presente artigo utiliza-se a expressão intersexualidade e intersexual, considerando que estas designações são mais compreensivas para as áreas das Ciências Humanas e das Ciências Sociais.

Em termos biomédicos, os DDS classificam-se em quatro grandes grupos: o pseudo-hermafroditismo feminino (o sexo cromossômico é 46 XX, o indivíduo possui ovário, mas a genitália externa é "ambígua"); o pseudo-hermafroditismo masculino (o sexo cromossômico é $46 \mathrm{XY}$, o indivíduo possui testículos, mas a genitália externa é feminina ou "ambígua"); a disgenesia gonadal mista (o indivíduo possui gônadas constituídas apenas por tecido fibroso, sem função hormonal nem capacidade de produção de gametas, e sem estruturas que permitam caracterizá-las como ovários ou testículos); e o hermafroditismo verdadeiro (pessoas que possuem tanto tecido ovariano quanto testicular, em geral associada à ambigüidade genital interna e externa) ${ }^{2}$.

\section{Os impactos multidisciplinares e o tratamento adequado}

Atento à complexidade do fenômeno, o Conselho Federal de Medicina (CFM) editou, em 2003, a Resolução no 1.664, que estabelece a conduta adequada ao tratamento de pessoas intersexuadas. De acordo com este documento, faz-se necessária uma conduta de investigação precoce em virtude de a intersexualidade poder vir a se configurar em uma urgência biológica e social ${ }^{3}$.

A urgência biológica se caracteriza nos casos de risco de vida, como no caso de Hiperplasia Adrenal Congênita da forma perdedora de sal, que, se não tratada de imediato, pode levar o neonato à morte. Já a urgência social se qualifica em virtude dos impactos psicológicos e sociais que o nascimento da criança intersexuada ocasiona para a família e para o próprio paciente, além dos graves transtornos à vida e ao bem estar do indivíduo em casos de erro da definição sexual, seja por ocasionar caracteres sexuais secundários opostos ao sexo previamente definido, bem como pela possibilidade da degeneração maligna das gônadas².

Portanto, devido aos riscos e aos consequentes impactos na vida do indivíduo, o CFM 
estabelece como obrigatória a presença de uma equipe multidisciplinar para a definição final e adoção do sexo, consoante explicita o artigo $4^{\circ}$ da Resolução no 1.664/2003:

Art. $4^{0}$ - Para a definição final e adoção do sexo dos pacientes com anomalias de diferenciação fazse obrigatória a existência de uma equipe multidisciplinar que assegure conhecimentos nas seguintes áreas: clínica geral e/ou pediátrica, endocrinologia, endocrinologia-pediátrica, cirurgia, genética, psiquiatria, psiquiatria infantil; $[\ldots]$

Parágrafo 40 - A critério da equipe médica outros profissionais poderão ser convocados para o atendimento dos casos.

O objetivo principal da equipe não é apenas o de descobrir qual a etiologia do fenômeno, mas, sim, obter uma definição racional sobre o sexo de criação mais recomendável. Em face das implicações do diagnóstico, com repercussões além dos aspectos biomédicos, tem-se compreendido como necessária também a presença de Psicólogos, Assistentes Sociais e profissionais do Direito ${ }^{13,14,15}$.

O acompanhamento psicológico da criança intersexuada e da sua família é fundamental para lidar com a atmosfera de incertezas e preconceitos que decorre do nascimento de um bebê que destoa dos padrões culturais de normalidade. Os sentimentos de culpa, de angustia, de medo, de superproteção e de ansiedade permeiam o núcleo familiar, abalando significativamente a sua dinâmica. Ao mesmo tempo, a situação demanda da família uma atitude capaz de enfrentar as dúvidas, assegurar cuidado, amor e aceitação ao neonato ${ }^{21,22}$.

A criança, por sua vez, além de lidar com um tratamento médico que poderá se prolongar por toda a vida, com a realização regular de exames e a ingestão de medicamentos, ainda poderá enfrentar questões de autoaceitação, sexualidade, preconceito social, dentre outros aspectos. Por isto, diante de tais situações, o acompanhamento psicológico faz-se necessário para aumento da capacidade de tolerância perante conflitos e tensões e, consequentemente, para a melhoria da qualidade de vida dos envolvidos $22,23,24$.

A atuação do Assistente Social na equipe visa assegurar o suporte emocional e social ao paciente e à sua família. Ao Serviço Social cabe a investigação e o entendimento sobre o agrupamento familiar da criança e a rede social, para capturar o grau de entendimento desta família sobre o diagnóstico, o quanto ela será capaz de absorver das informações e orientações recebidas sobre o tema e a forma como se posicionará diante da nova realidade, para fazer com que se sintam acolhidos e apoiados pela equipe, intermediando e esclarecendo adequadamente quanto à problemática e aos prognósticos ${ }^{14}$.

Por fim, a presença de operadores do Direito na equipe vem sendo reconhecida como um ele- mento constitutivo essencial para garantir, juntamente com os profissionais de Serviço Social, a concretização dos Direitos Humanos inerentes a este segmento populacional, com destaque para o direito à saúde e o direito à identidade, cuja garantia com total prioridade é determinada em lei em virtude da condição peculiar de pessoa em desenvolvimento $4,11,23$.

No que tange à garantia do direito à identidade, a atuação dos operadores do Direito é fundamental, sobretudo nas Ações para Retificação de Registro Civil de crianças intersexuadas. Tendo em vista que a Lei de Registros Públicos - LRP determina que o assentamento de nascimento seja efetuado de imediato, com a necessária indicação do nome e do sexo do neonato, muitas vezes o sexo indicado pela família da criança intersexuada não condiz com o sexo designado posteriormente pela equipe de saúde, fazendo-se necessário o ajuizamento de uma ação no Judiciário com o fito de retificar as informações contidas no Registro Civil desta criança ${ }^{23}$.

Neste sentido, o Direito articula-se com a "intersexualidade", dentre outros aspectos, a partir do elemento civil que integra a identidade sexual do ser humano, designado no momento do Assentamento de Nascimento da criança. Ou seja, a discussão sobre o tema "intersexualidade", em um viés jurídico, ocorre ao se considerar a identidade sexual como um subaspecto do Direito Humano personalíssimo à identidade, intimamente relacionado ao princípio da dignidade da pessoa humana ${ }^{16,23}$. E, especificamente na presente investigação, essa articulação é construída a partir da discussão sobre a garantia do direito à identidade da criança com intersexo na perspectiva do Registro Civil de Nascimento como um Direito Humano.

No ambulatório no qual se realizou o levantamento constatou-se que algumas famílias, temerosas de antecipar o registro consignando o sexo equivocado, preferiram retardar o registro das suas crianças. Tal medida familiar se pauta na expectativa da definição sexual. No entanto, a inexistência do registro civil da criança defronta-se com o limite do acesso da criança aos serviços de saúde, para usufruir eventuais benefícios de seguro, para uso de transporte aéreo ou intermunicipal.

\section{0 direito à identidade}

O direito à identidade, que tem início formal a partir do Assentamento Civil de Nascimento do indivíduo, é um Direito Humano intimamente ligado ao princípio da dignidade da pessoa humana. Ele integra o rol dos direitos da personalidade, ou seja, daqueles direitos que têm por objeto os atributos físicos, psíquicos e morais da pessoa em si, os seus prolongamentos e as suas projeções sociais ${ }^{24}$.

A idéia de personalidade encontra-se ligada à pessoa, pois revela a aptidão genérica para adquirir direitos e contrair deveres. Hoje, representando uma conquista da civilização jurídica, esta 
aptidão é reconhecida a todo ser humano, conforme previsto e tutelado pela Declaração Universal dos Direitos Humanos e pela Convenção Americana sobre Direitos Humanos ${ }^{25,26}$. Sob tal perspectiva, a personalidade é concebida como o ponto de apoio dos direitos e obrigações do individuo e é partir dela que são irradiados todos os demais Direitos Humanos ${ }^{27}$.

Os direitos da personalidade são direitos essenciais ao desenvolvimento da pessoa, uma vez que se destinam a resguardar a sua dignidade e incluem elementos internos e externos do indivíduo, bem como o seu aspecto social ${ }^{27}$. Em verdade, muitos dos direitos fundamentais, entendidos como aqueles Direitos Humanos objetivamente previstos em uma ordem jurídica concreta, são direitos da personalidade. Em linhas gerais, tais direitos envolvem o direito à vida, à identidade, à liberdade, ao próprio corpo, à incolumidade física, à proteção da intimidade, à integridade moral, à preservação da própria imagem, e a tudo mais que seja digo de proteção, amparo e defesa pelo ordenamento jurídico ${ }^{28}$.

No âmbito constitucional brasileiro, o direito à identidade encontra-se representado através do principio fundamental da dignidade da pessoa humana (inc. III, art. $1^{\circ}, \mathrm{CF} / 88$ ), uma vez que a afirmação da identidade humana, no que tange a possibilidade de possuir e expressar todos os atributos e características pessoais, singulares, intransmissíveis e irrenunciáveis, constitui uma realização da própria dignidade do sujeito6, 16, 23.

No ordenamento infraconstitucional, o Código Civil de 2002 inovou ao trazer expressamente um espaço dedicado aos direitos da personalidade: Titulo I - Das Pessoas Naturais, Capítulo II Dos direitos da personalidade, artigos 11 a 21 . 0 Código estabelece normas que asseguram proteção aos direitos da personalidade, embora não os especifique, salvo o direito à integridade física, o direito ao nome e à proteção da imagem ${ }^{29}$.

Ademais, na esfera do Direito da Criança e do Adolescente a proteção do direito à identidade também se encontra expressamente prevista na Convenção dos Direitos da Criança, a qual estabelece, em seu artigo $8^{\circ}$, que o Estado tem a obrigação de proteger e, se necessário, de restabelecer os aspectos fundamentais da identidade da criança?. No âmbito nacional, o Estatuto da Criança e do Adolescente afirma, em seus artigos 15 e 17, que a criança tem direito à liberdade, ao respeito e à dignidade, como pessoas humanas em processo de desenvolvimento e como sujeitos de direitos, sendo a identidade indispensável ao pleno gozo da dignidade ${ }^{5}$.

Além de se constituir como direito, a identidade é um instrumento fundamental para a individualização social e jurídica do ser humano, e que pode ser compreendida como a projeção pública da sua personalidade 27,28 . Diversos são os bens jurídicos integrantes da identidade humana, dentre os quais se destacam a identidade sexual e o nome, atributos essenciais ao Assentamento Civil de Nascimento e, ao mesmo tempo, obstáculos concretos em casos de registros de crianças intersexuadas ${ }^{23,30}$.

O sexo é um dos principais elementos de identidade humana, pois indica o conjunto de características psicofísicas que distinguem o macho da fêmea. Neste sentido, o sexo civil ou legal, designado por ocasião do Assentamento de Nascimento da Criança, consiste na determinação do sexo em razão da vida civil de cada pessoa, em suas relações na sociedade, com inúmeras repercussões na seara jurídica ${ }^{12}$.

Diretamente ligado ao sexo, uma vez que o prenome será feminino ou masculino baseado no sexo do individuo, o nome civil é o elemento designativo do ser humano e fator de sua identificação na sociedade, individualizando a pessoa no seio social e indicando a sua procedência familiar. Expressamente previsto pelo Código Civil de 2002, a toda pessoa é garantido o direito ao nome ${ }^{29}$.

O nome civil, por seus aspectos privado e público, importa, ao mesmo tempo, um direito e um dever, envolvendo um direito subjetivo e um interesse social. Sob o aspecto privado, é direito de todo ser humano possuir um nome e ser identificado na sociedade por meio deste. Em relação ao aspecto público, a Lei de Registros Públicos estabelece como obrigação o registro do nome do registrando no Assentamento de Nascimento ${ }^{1}$. Ou seja, o Registro Civil do nome permite ao indivíduo o seu reconhecimento não apenas no plano fático, mas também no mundo jurídico, garantindo-lhe acesso aos seus direitos e obrigações ${ }^{27,} 30$.

Entretanto, apesar de serem elementos fundamentais à identidade do indivíduo, a obrigação da imediata indicação do sexo e do nome da criança no Assentamento Civil de Nascimento, conforme previsão expressa da Lei 6.015/73, constituise em uma barreira para muitas das crianças com intersexo.

\section{O desafio do assentamento civil de crianças intersexuadas}

Considerando que a identidade da pessoa constitui sua primeira inserção na cidadania e na vida relacional, o registro da criança logo após o nascimento constitui um direito, assegurado no plano dos Direitos Humanos, na esfera dos Direitos da Criança e também no âmbito do ordenamento jurídico brasileiro $5-7,25,26,29$. O Assentamento Civil da pessoa natural afigura-se como sua própria condição civil, pois lhe assegura direitos já estabelecidos e afirma o indivíduo como pessoa ${ }^{1}$.

Apesar de tutelar os direitos da personalidade, no que tange ao Registro Civil de Nascimento, o Código Civil de 2002 limita-se a determinar a sua inscrição ou averbação, deixando a normatização casuística dos assentos para legislação específica. Neste caso, a norma que dispõe sobre o registro civil de nascimento é a Lei no 6.015/1973 - LRP, especificamente no seu Titulo II, Capítulo IV. 
A LRP torna obrigatório o Assentamento Civil de Nascimento e estabelece um prazo de 15 dias para registro de todo nascimento havido no território nacional (art. 50). Contudo, a lei prevê algumas exceções em relação ao prazo de registro. Prevê-se a ampliação do prazo em até três meses na hipótese em que o local de nascimento diste de mais de trinta quilômetros da sede do cartório (art. 50). Enquanto na hipótese de nascimento ocorrido a bordo de navios ou aeronaves, o prazo de registro é de cinco dias, a contar do desembarque no local de destino (art. 51).

A lei especifica, ainda, os obrigados a fazer a declaração de nascimento (art. 52), inclusive estendendo a obrigatoriedade do registro daquelas crianças nascidas mortas ou que vieram a óbito na ocasião do parto (art. 53). No que diz respeito ao conteúdo do assento de nascimento, estabelece a LRP o dever de conter o sexo do registrando e o nome e prenome que forem postos à criança, dentre outros elementos (art. 54).

Ocorre que o nascimento de crianças intersexuadas muitas vezes impõe um limite objetivo ao Assentamento Civil destes indivíduos, em face da impossibilidade da declaração imediata do sexo e, consequentemente, do prenome dessas crianças. No Brasil, o sexo civil tem como base unicamente o sexo morfológico do indivíduo e, em casos de crianças com genitália ambígua, torna-se inviável o seu registro imediato, em razão da incerteza quanto ao sexo e ao nome, feminino ou masculino, do neonato.

A situação gera discussões entre os operadores do direito e entre os profissionais de saúde, uma vez que, se a família optar pelo retardamento do registro civil da criança até que se concluam os resultados dos exames e da definição sexual pela equipe multidisciplinar, esta criança não existirá no plano jurídico e, consequentemente, não terá os seus direitos assegurados.

Por outro lado, ao optar pelo registro imediato do neonato, corre-se o risco de se incidir na necessidade de uma posterior Ação de Retificação do Registro Civil, a fim de corrigir o nome e o sexo civil, que não correspondem ao sexo definido após os procedimentos médicos, uma vez que a LRP não prevê qualquer hipótese especial de retificação do prenome em virtude do estado intersexual, ou qualquer tipo de procedimento mais célere nestes casos.

Desta forma, o único meio para a retificação do registro, nestes casos, é a via judicial, segundo os preceitos da própria Lei 6.015/73:

"Art. 57. A alteração posterior de nome, somente por exceção e motivadamente, após audiência do Ministério Público, será permitida por sentença do juiz a que estiver sujeito o registro, arquivandose o mandado e publicando-se a alteração pela imprensa, ressalvada a hipótese do art. 110 desta Lei."

Ainda de acordo com a referida norma, o interessado na retificação deve requerer, em petição fundamentada e instruída com documentos e/ou com indicação de testemunhas, que o juiz a ordene, ouvido o órgão do Ministério Público e os interessados, no prazo de cinco dias (art. 109). Entretanto, seja em virtude do volume de processos que o Magistrado precisa despachar, ou ainda em razão do volume de ações nas quais o Promotor de Justiça precisa emitir seu parecer, dentre outras razões, na prática, é notório que o tempo requerido para a resolução de uma demanda judicial é extenso.

Neste sentido, a Ação de Retificação do Registro Civil da criança intersexuada torna-se mais um ponto de tensão para a família, uma vez que se trata de um desgaste emocional e temporal, além daqueles já inerentes ao fenômeno. Ademais, há uma violação ao direito à identidade da criança e à sua dignidade durante este período.

Sob esta óptica, o nascimento de crianças intersexuadas enseja um verdadeiro tensionamento diante da realidade, que suscita uma reflexão sobre a ordem normativa vigente: Como garantir os direitos da criança em face da sua dignidade? Por meio da defesa do seu Registro de Nascimento imediato, para posterior retificação desse Registro quando diagnosticado o sexo oposto àquele inicialmente designado? Ou por meio de uma via prioritária e simplificada na análise dos processos de retificação de Registro? Ou defender o direito a um Registro Especial provisório por um período suficiente para o efetivo diagnóstico do bebê?

\section{As entrevistas}

Diversos foram os aspectos e perspectivas apontados que podem ser priorizados ao se defender uma das opções atualmente existentes. Ora se toma como referência a criança, enquanto sujeito de direitos e pessoa em peculiar estado de desenvolvimento, fazendo-se necessário torná-la juridicamente existente, com total prioridade, para que possa ser assegurada a sua condição civil; ora se toma como base sua família, visando minimizar os seus conflitos, tensões e constrangimentos, além de todos aqueles já inerentes ao fenômeno, evitando-se o trâmite de uma ação judicial; ou ainda se toma como referência a necessidade de acesso a serviços essenciais, para os quais o Assentamento Civil se faz indispensável, ou o atendimento ao próprio comando legal, dentre outros aspectos.

Especificamente em relação à Lei de Registros Públicos, o posicionamento majoritário dos entrevistados foi no sentido de que tal diploma, nos termos em que se encontra atualmente, não cumpre com o papel de tutela e resguarda do direito à identidade das crianças intersexuadas, fazendo-se necessário repensar a ordem normativa vigente a fim de que se possa garantir e atingir a sua plena dignidade. Em verdade, muito foi dito a respeito do caráter excludente da atual legislação em relação a este segmento social.

O "juiz A" afirmou: "Ora, é indigno que a pessoa que precisa ainda do acolhimento médico, de cuidados, com tempo, não tenha um Registro. Como 
também é índigo que essa pessoa tenha um Registro equivocado e definitivo.". Ressaltou que, em sua opinião, deveria haver uma "terceira alternativa", que a sociedade já deveria ter compreendido que existem situações diferentes, não apenas a existência do sexo feminino e masculino, e se assim não o fez, o princípio da dignidade da pessoa humana encontra-se comprometido.

Por outro lado, o "juiz B" ponderou que, apesar da legislação vigente apresentar defeitos e precisar de mudanças para abarcar as situações peculiares, a Lei de Registros Públicos resguarda a dignidade das crianças intersexuadas na medida em que, uma vez registradas, a elas são garantidos todos os direitos inerentes à pessoa humana. Ademais, salientou que, nestes casos, o registro pode ser retificado a qualquer momento, por meio de uma ação relativamente simples.

Já o posicionamento do "juiz C" foi no sentido da perfeita sintonia da LRP com a garantia do direito à identidade e dignidade da criança intersexuada, não havendo nenhuma forma de exclusão da referida norma ao segmento populacional em comento, inclusive porque o próprio magistrado, nestes casos, pode resolver a situação da indefinição provisória do sexo no Assentamento Civil deixando tal espaço em branco, para posterior inclusão, quando de posse do diagnostico definitivo.

Uma solução provisória adotada pelo "juiz B" diante da situação das crianças com genitália ambígua, durante o tempo em que esteve atuando na Vara de Registros Públicos, foi a escolha de um Cartório específico na região para o recebimento dos casos de Registros Civil dessas crianças. Dentre os servidores do Cartório foi selecionado um, no qual confiava, que ficava encarregado de tais Registros, tendo sido-Ihe determinado que deixasse o campo do sexo em branco, ou adotasse o escolhido pelos pais, para que, quando fosse informado do diagnóstico final proferido pela equipe médica, ele mandasse retificar diretamente no Cartório, sem a necessidade do trâmite de uma Ação de Retificação de Registro.

O "juiz B" comentou que assim procedeu durante em certo período, mas que não conseguiu dar continuidade porque o número de processos em sua vara aumentou consideravelmente ao longo do tempo, alcançando um ponto em que não mais conseguia separar aqueles que eram prioritários. Por fim, sugeriu que assunto do Assentamento Civil de crianças intersexuadas fosse levado e discutido junto à Corregedoria do Tribunal de Justiça, a fim de que tal órgão judicial emitisse um provimento determinando a conduta adequada para a situação, uma vez que, a partir de então, qualquer oficial de cartório poderia seguir aquele procedimento, sem a necessidade de uma ação judicial para a retificação do Registro.

Algumas outras alternativas foram levantadas pelos demais entrevistados, a fim de tentar assegurar o direito à identidade e a dignidade da criança com intersexo sobre a perspectiva do seu Assentamento Civil, dentre as quais: 1) Aceitar um Registro provisório da criança, com o seu prenome preenchido como RECÉM NASCIDO e o seu sexo em branco, até que se tenha a definição final do sexo e do nome; 2) Criar um sistema de prioridade para as Ações de Retificação de Registro Civil oriundas de crianças com intersexo; 3) Estabelecer de um terceiro gênero no Assentamento Civil de Nascimento, para os casos de indivíduos intersexuados.

Portanto, múltiplos são os caminhos que podem conduzir à garantia do direito à identidade dessas crianças, contudo a presente investigação não visa ponderar sobre aquele que melhor satisfaz a questão, mas, sim, sobressaltar a problemática do Assentamento Civil das crianças intersexuadas, a fim de que a sua discussão seja o primeiro passo rumo à mudança no paradigma vigente e, desta forma, que a Ciência Jurídica, junto com as Ciências da Saúde, se torne mais um pilar de sustentação e proteção da dignidade dessas crianças, e não mais um obstáculo a ser superado.

O direito à identidade é um direito fundamental personalíssimo, intimamente ligado à dignidade da pessoa humana, reconhecido a todo o ser humano e resguardado por importantes instrumentos normativos, como a Declaração Universal dos Direitos Humanos, a Convenção dos Direitos da Criança, a Constituição Federal do Brasil e o Código Civil de 2002. O seu início formal se dá a partir do Assentamento Civil de Nascimento, que se afigura como a própria condição civil, assegurando direitos já estabelecidos e afirmando o indivíduo como pessoa.

Contudo, a Lei de Registros Públicos brasileira torna-se uma barreira legítima para a concretização do direito à identidade de crianças intersexuadas, uma vez que determina o imediato registro do recém nascido com um nome e sexo, não contemplando a situação da indefinição sexual provisória deste segmento populacional.

Neste contexto, as famílias das crianças intersexuadas encontram-se diante de duas opções concretas: registrar a criança sem o diagnóstico sexual definitivo, correndo-se o risco de uma posterior retificação desse Registro quando diagnosticado o sexo oposto àquele inicialmente designado; ou retardar o Registro Civil desta criança, deixando-a, entretanto, sujeita à inexistência jurídica e, consequentemente, sem acesso aos seus direitos durante o período do diagnóstico.

A decisão quanto ao retardamento do Assentamento Civil ou a sua realização, sob o risco de posterior retificação no que tange ao nome e ao sexo civil, é objeto de dúvidas e discussões não apenas entre os pacientes e os seus familiares, mas também entre os profissionais atuantes. Não há um posicionamento unânime entre os profissionais do Direito, o que se torna mais um foco de tensão para a família e a para a criança. 
Constata-se que a Medicina vem desempenhando o seu papel no que diz respeito ao desenvolvimento de pesquisas, exames e tratamentos especializados para este segmento populacional, visando minimizar os impactos decorrentes do fenômeno e o tempo em que a criança encontra-se sem definição sexual. Entretanto, cumpre ao Direito, enquanto ciência social, acompanhar e refletir o progresso e a evolução da sociedade, o que significa, in casu, buscar ferramentas que ga-

\section{REFERÊNCIAS}

1. Brasil. Lei no 6.015. Dispõe sobre os registros públicos e dá outras providências (31 de Dezembro de 1973) [acesso em 03 abr 2012]. Disponível em: http://www.planalto.gov.br/ ccivil_03/leis/L6015.htm.

2. Maciel-Guerra AT, Guerra Junior G. Classificação. In: Maciel-Guerra AT, Guerra Junior G. Menino ou Menina? Distúrbios da Diferenciação do Sexo. $2^{a}$ ed. Rio de Janeiro: Rubio; 2010. p. 89-95.

3. Conselho Federal de Medicina. Resolução n. o 1.664. Dispõe sobre as normas técnicas necessárias para o tratamento de pacientes portadores de anomalias de diferenciação sexual. Publicada no DOU n. 90 de 13 maio 2003, Seção 1. p. 101-2 (12 de Maio de 2003).

4. Sales IG, Fraser RTD, Lima IMSO, Toralles MBP. Direitos Humanos de Jovens com Intersexo: Por um Serviço de Genética Medica Resoluto. In: Reis V, organizadora. Juventudes do Nordeste do Brasil, da America Latina e do Caribe. v. 3. Brasilia: FLACSO; 2009. p. 97134.

5. Rossato LA, Lepore PE, Cunha RS. Estatuto da criança e do adolescente comentado. São Paulo: Editora Revista dos Tribunais; 2010.

6. Junior NN, Nery RMA. Constituição Federal comentada e legislação constitucional. São Paulo: Editora Revista dos Tribunais; 2006.

7. Organização das Nações Unidas (ONU). Convenção sobre os Direitos da Criança. Adotada e proclamada pela Resolução 1386 da Assembléia Geral das Nações Unidas (20 de novembro de 1989). Promulgada na República Federativa do Brasil com o Decreto no 99.710/ 90 [acesso em 03 abr 2012]. Disponível em: http://www.planalto.gov.br/ccivil_03/decreto/ 1990-1994/D99710.htm.

8. Coelho LAL. Ator e Identidade. In: Bastos LC, Lopes LPM, organizadores. Estudos de Identidade: entre saberes e práticas. Rio de Janeiro: Rubio; 2010. p. 157-70.

9. Guerra Junior G, Maciel-Guerra AT. Avaliação Clínica e Laboratorial. In: Maciel-Guerra AT, Guerra Junior G. Menino ou Menina? Distúrbios da Diferenciação do Sexo. $2^{a}$ ed. Rio de Janeiro: Rubio; 2010. p. 315-21. rantam o direito à identidade de crianças intersexuadas.

Isto significa repensar a ordem normativa vigente e criar soluções concretas, principalmente por se tratar do segmento infantil - pessoas em peculiar estado de desenvolvimento, carecedoras de proteção e prioridade absolutas, a fim de que a dignidade das crianças intersexuadas, princípio fundamental do ordenamento jurídico pátrio, seja adequadamente resguardada pelo Direito.

10. Santos MMR, Araújo TCCF. Estudos e Pesquisas sobre a Intersexualidade: Uma Análise Sistemática da Literatura Especializada. Psicologia: Reflexão e Critica. 2008; 21(2): 267-74. http://dx.doi.org/10.1590/S010279722008000200012>.

11. Canguçu-Campinho AKF, Bastos ACSB, Lima IMSO. O discurso biomédico e o da construção social na pesquisa sobre intersexualidade. Physis Revista de Saúde Coletiva. 2009; 19: 1145-64. http://dx.doi.org/10.1590/S010373312009000400013.

12. Choeri RCS. O Conceito de Identidade e a Resignação Sexual. Rio de Janeiro: Renovar; 2004.

13. Machado PS. O sexo dos anjos: um olhar sobre a anatomia e a produção do sexo (como se fosse) natural. Cadernos Pagu. 2005; 24 : 24981. http://dx.doi.org/10.1590/S010483332005000100012.

14. Bitterncourt ZZLC, Ceschini M. Aspectos Sociais. In: Maciel-Guerra AT, Guerra Junior G. Menino ou Menina? Distúrbios da Diferenciação do Sexo. 2a ed. Rio de Janeiro: Rubio; 2010. p. 381-91.

15. Silva RBP, Suzigan LZC. Aspectos Psicológicos. In: Maciel-Guerra AT, Guerra Junior G. Menino ou Menina? Distúrbios da Diferenciação do Sexo. $2^{a}$ ed. Rio de Janeiro: Rubio; 2010. p. 374-9.

16. Torres JHR. Dignidade sexual e proteção no sistema penal. Rev. bras. crescimento desenvolv. hum. [periódico online]. 2011 [acesso em 17 set 2011]; 21(2). Disponível em: http://www.revistasusp.sibi.usp.br/ scielo.php?script =sci arttext\&pid=S0104$12822011000200001 \&$ Ing $=$ pt\&nrm =isso.

17. Melucci A. Por uma sociologia reflexiva Pesquisa Qualitativa e Cultura. Petrópolis: Vozes; 2005.

18. Demo P. Metodologia do Conhecimento Científico. São Paulo: Atlas; 2000.

19. Douville O. Para que serve o nome que carrego, quando minhas culturas se desmancham? Ágora (Rio J.) [periódico online]. 2011 [acesso em 28 dez 2011]; 14(1). Disponível em: <http://dx.doi.org/10.1590/S1516$14982011000100003>$. 
20. Damiani D, Guerra-Junior G. As novas definições e classificações dos estados intersexuais: o que o Consenso de Chicago contribui para o estado da arte? Arq Bras Endocrinol Metab. 2007; 51(6). http:// d x.doi.org/10.1590/S0004 27302007000600018

21. Canguçu-Campinho AKF. Aspectos da construção da maternidade em mulheres com filhos intersexuais [dissertação]. Salvador: Instituto de Saúde Coletiva da Universidade Federal da Bahia; 2008.

22. Spinola-Castro AM. A Importância dos Aspectos Éticos e Psicológicos na Abordagem do Intersexo. Arq Bras Endocrinol Metab. 2005; 49(1). http://dx.doi.org/10.1590/S000427302005000100007

23. Lima IMSO, Toralles MBP, Fraser RTD. Direitos da criança e disturbios da diferenciação do sexo: além da família. In: Maciel-Guerra AT, Guerra Junior G. Menino ou Menina? Distúrbios da Diferenciação do Sexo. $2^{a}$ ed. Rio de Janeiro: Rubio; 2010. p. 479-498.

24. Gagliano OS, Pamplona Filho R. Novo curso de direito civil. v. 1. $2^{a}$ ed. São Paulo: Saraiva; 2002.

25. Organização das Nações Unidas (ONU). Declaração Universal dos Direitos Humanos.
Adotada e proclamada pela Resolução 217 A (III) da Assembléia Geral das Nações Unidas em 10 de dezembro de 1948 [acesso em 03 abr 2012]. Disponível em: http:// portal.mj.gov.br/sedh/ct/legis_intern/ ddh_bib_inter_universal.htm.

26. Organização dos Estados Americanos (OEA). Convenção Americana de Direitos Humanos. Promulgada na República Federativa do Brasil através do Decreto no 678 (22 de novembro de 1969) [acesso em 03 abr 2012]. Disponível em: http://www.planalto.gov.br/ccivil_03/ decreto/D0678.htm.

27. Pereira CMS. Instituições de Direito Civil. v. 1. 20a ed. Rio de Janeiro: Forense; 2004.

28. Elesbao EC. Os direitos da personalidade no novo Código Civil brasileiro. In: Castro AMO et al. Pessoa, Gênero e Família: Uma Visão Integrada do Direito. Porto Alegre: Livraria do Advogado; 2002. p. 9-34.

29. Brasil. Lei 10.406. Institui o Código Civil (10 de janeiro de 2002) [acesso em 03 abr 2012]. Disponível em: http://www.planalto.gov.br/ ccivil_03/leis/2002/L10406compilada.htm.

30. Vieira TR. Nome e Sexo: mudanças no registro civil. São Paulo: Editora Revista dos Tribunais; 2008. 